\title{
Sulphydryl blocker induced small intestinal inflammation in rats: a new model mimicking Crohn's disease
}

D Rachmilewitz, E Okon, F Karmeli

\begin{abstract}
Background-Sulphydryl compounds are essential for maintaining mucosal integrity in the gastrointestinal tract.

Aim-To characterise a model of experimental inflammation in the small intestine induced by a sulphydryl blocker.

Methods-Inflammation in the small intestine was induced in rats by intrajejunal administration of $0.1 \mathrm{ml} 2 \%$ iodoacetamide. The possible amelioration of the damage induced was modulated by intragastric administration of TEMPOL (4hydroxy-2,2,6,6-tetramethylpiperidine-1oxyl; $50 \mathrm{mg} / 100 \mathrm{~g}$ body weight), ketotifen ( $200 \mu \mathrm{g} / 100 \mathrm{~g}$ body weight) or by addition of L-NAME $\left(\mathrm{N}^{\mathrm{G}}\right.$-nitro-L-arginine methyl ester; $0.1 \mathrm{mg} / \mathrm{ml})$ or apocynin $(120 \mu \mathrm{g} / \mathrm{ml})$ to the drinking water. Rats were sacrificed at various time intervals, the small intestine resected, weighed, macroscopic lesions were assessed, and mucosal generation of inflammatory mediators and nitric oxide synthase activity were determined.
\end{abstract}

Results-Intrajejunal administration of iodoacetamide induced, after one week, multifocal mucosal erosions, ulcerations with granulomas and giant Langhans cells. At two weeks, the mucosa was almost macroscopically intact but histologically epithelial granuloma and giant cells were present. Myeloperoxidase activity was increased in the first 24 hours, one week later mucosal nitric oxide synthase activity and generation of leukotriene $B 4$, leukotriene $\mathrm{C} 4$ and thromboxane $\mathrm{B} 2$ were increased, whereas prostaglandin E2 generation was decreased notably. Ketotifen and apocynin significantly decreased the extent of injury which was not affected by TEMPOL or L-NAME.

Conclusions-Jejunal inflammation induced by the sulphydryl blocker, iodoacetamide, resembles the pathological changes in Crohn's disease. The protective effect of ketotifen and apocynin indicates the contribution of $\mathrm{O}_{2}^{-}$and pro-inflammatory mediators to the pathogenesis of the damage, and may be a novel approach to the treatment of inflammatory bowel disease.

(Gut 1997; 41: 358-365)

Keywords: iodoacetamide; TEMPOL; ketotifen; apocynin; NO synthase
The aetiology of inflammatory bowel disease (IBD) is still not known. However, available evidence suggests that the pathogenesis of IBD involves interaction among genetic susceptibility, immunological factors and the environment, especially bacteria. Experimental models, though all of them far from mimicking human IBD, permit identification of possible early events, provide an understanding of the interaction among the various components and permit evaluation of possible new therapeutic modalities. ${ }^{1}$ Nevertheless, most models are confined to inflammation in the large bowel. Only a few models are applicable to the small intestine, which is affected to the same extent as the large bowel in Crohn's disease. The different area of involvement may be due to an environmental factor and mainly due to the presence or absence of bacteria. The models affecting the small intestine are the trinitrobenzene sulphonic acid (TNB)/ethanol, ${ }^{2}$ indomethacin, ${ }^{3}$ PG-PS, ${ }^{4}$ HLA-B27/ $\beta_{2}$ MTG, ${ }^{5}$ and the interleukin-10 knock out mice. ${ }^{6}$ Granuloma formation, which is characteristic of human Crohn's disease, was reported in only a few models. ${ }^{78}$

Recently, we have reported a new model of colonic inflammation induced by a sulphydryl (SH) blocker, iodoacetamide. ${ }^{9}$ This reproducible model of colonic inflammation highlights the important contribution of $\mathrm{SH}$ compounds in maintaining mucosal integrity. The extent of inflammation in this model was ameliorated by inhibition of nitric oxide (NO) synthesis, indicating the important contribution of NO to the pathogenesis of inflammation and suggesting that this approach may be of value in the treatment of IBD.

The aim of this study was to evaluate whether iodoacetamide induces small intestinal inflammation, to characterise its effects in the small bowel and possibly also to modulate the extent of inflammation by novel modalities, such as a potent free radical scavenger, 4-hydroxy-2,2,6,6-tetramethylpiperidine-1oxyl (TEMPOL), ketotifen or by inhibition of the generation of $\mathrm{NO}$ or reactive oxygen species.

\section{Methods}

Iodoacetamide, methyl cellulose, L-arginine, L-citrulline, L-NAME ( $\mathrm{N}^{\mathrm{G}}$-nitro-L-arginine methyl ester), NADPH, valine, aminoguanidine, dithiothreitol, phenylmethylsulphonyl fluoride, EDTA, and EGTA were purchased from Sigma Chemical Co, St Louis, Missouri,
Accepted for publication 10 March 1997 
USA. Dowex AG50W-X8 (Na form) 100-200 mesh, and Tris base (electrophoresis grade) were purchased from BioRad Laboratories, Richmond, California, USA. Aquasol-2 was purchased from DuPont Co/NEN Research Products, Bad Hamburg, Germany. TEMPOL was purchased from Aldrich Chemical Co., Milwaukee, MI, USA. Iodoacetamide and ketotifen were purchased from Sigma, Israel; apocynin was purchased from Carl Roth $\mathrm{GmbH}$, Karlsruhe, Germany.

\section{ANIMALS}

Male Sprague-Dawley rats, weighing 200$250 \mathrm{~g}$ and fed ad libitum, were used in all studies.

IODOACETAMIDE INDUCED SMALL INTESTINAL INFLAMMATION

In the first series of experiments, laparotomy was performed under light ether anaesthesia. The jejunum was identified, rats were injected intrajejunally with $0.1 \mathrm{ml}$ iodoacetamide $(2 \%)$, suspended in methyl cellulose $(1 \%)$ and the abdominal wall was immediately closed. In another series of experiments, animals were anaesthetised by Na-Pentobarbital (3 mg/ $100 \mathrm{~g}$ intraperitoneally). The abdominal wall was opened, the jejunum identified, a $10 \mathrm{~cm}$ loop was closed and injected with $0.1 \mathrm{ml}$ iodoacetamide $(2 \%)$ in methyl cellulose. Control rats were injected with $0.1 \mathrm{ml}$ methyl cellulose. Thirty minutes later, the loop was opened, returned to the abdominal cavity and the abdominal wall was closed. In other experiments rats were treated for up to 28 days with $0.1 \%$ iodoacetamide added to the drinking water. To assess possible pharmacological modulation of iodoacetamide induced small intestinal inflammation, groups of rats were treated intragastrically, daily, with TEMPOL $(50 \mathrm{mg} / 100 \mathrm{~g})$ or with ketotifen $(200 \mu \mathrm{g} / 100 \mathrm{~g})$ immediately after the intraluminal administration of iodoacetamide. In other experiments, L-NAME $(0.1 \mathrm{mg} / \mathrm{ml})$ or apocynin $(120 \mu \mathrm{g} / \mathrm{ml})$ was added to the drinking water immediately after the intrajejunal administration of iodoacetamide. Daily water consumption was measured.

Rats were sacrificed by cervical dislocation one, seven and 14 days after iodoacetamide treatment. The small intestine was isolated and opened longitudinally. The proximal $25 \mathrm{~cm}$ segment was weighed and macroscopic damage was evaluated. Tissue samples were obtained for histological examination and the remaining mucosa was scraped and processed for determination of lipoxygenase products, thromboxane $\mathrm{B}_{2}\left(\mathrm{TXB}_{2}\right)$, prostaglandin $\mathrm{E}_{2}$ $\left(\mathrm{PGE}_{2}\right)$, myeloperoxidase (MPO), and nitric oxide synthase (NOS) activities.

DETERMINATION OF MUCOSAL DAMAGE

Mucosal damage in the affected proximal $25 \mathrm{~cm}$ jejunal segment was measured macroscopically and scored by multiplying the length $(\mathrm{mm})$ and width $(\mathrm{mm})$ of each mucosal lesion.
For each rat the total score was determined by summating the ulcer scores $\left(\mathrm{mm}^{2}\right)$. All measurements of damage were performed by two blinded observers using a stereomicroscope. The interobserver variability between the two observers was $7 \%$.

DETERMINATION OF NOS ACTIVITY

NOS activity was monitored by the conversion of $\left[{ }^{3} \mathrm{H}\right]$-L-arginine to citrulline according to Bush et al. ${ }^{10}$ Mucosal scrapings $(100 \mathrm{mg})$ were homogenised for 30 seconds at $4^{\circ} \mathrm{C}$ with a polytron (Kinematica $\mathrm{GmbH}$, Kriens-Luzern, Switzerland) in $0.9 \mathrm{ml}$ ice-cold $50 \mathrm{mM}$ Tris$\mathrm{HCl}, \mathrm{pH}$ 7.4, containing $0.1 \mathrm{mM}$ EDTA, $0.1 \mathrm{mM}$ EGTA, $0.5 \mathrm{mM}$ dithiothreitol, and $1 \mathrm{mM}$ phenylmethylsulphonyl fluoride. Homogenates were centrifuged at $20000 \mathrm{~g}$ for 60 minutes at $4{ }^{\circ} \mathrm{C}$ and the supernatant was used as the source of NOS. Enzymatic reactions were conducted at $37^{\circ} \mathrm{C}$ in $50 \mathrm{mM}$ Tris- $\mathrm{HCl}$, $\mathrm{pH}$ 7.4, containing $100 \mu \mathrm{M}$ L-arginine, $100 \mu \mathrm{M}$ NADPH, $2 \mathrm{mM} \mathrm{CaCl}, 0.2-0.4 \mathrm{mg}$ supernatant proteins, and approximately $200000 \mathrm{dpm} \mathrm{L}-\left[2,3,4,5-{ }^{3} \mathrm{H}\right]$-arginine $\mathrm{HCl}$ (77 Ci/mmol; Amersham, UK) to a final volume of $100 \mu \mathrm{l}$. In several experiments homogenates prepared from mucosal scrapings obtained from normal rats were incubated in the absence of $\mathrm{Ca}^{2+}$ or in the presence of 1-100 $\mathrm{mM}$ L-NAME, $10 \mathrm{mM}$ aminoguanidine or $60 \mathrm{mM}$ valine in the assay mixture. Enzymatic reactions were terminated by addition of $2.0 \mathrm{ml}$ ice-cold "stop buffer" $20 \mathrm{mM}$ sodium acetate, $\mathrm{pH} 5.5,1 \mathrm{mM}$ L-citrulline, $2 \mathrm{mM}$ EDTA, and $0.2 \mathrm{mM}$ EGTA. Citrulline was determined by loading the samples $(2.0 \mathrm{ml})$, prepared as described earlier, onto columns $(1 \mathrm{~cm}$ diameter) containing $1 \mathrm{ml}$ Dowex AG50W-X8, Na form, that had been preequilibrated with stop buffer. Columns were eluted with $4 \times 1.0 \mathrm{ml}$ water collected into scintillation vials. Opti-fluor $(10 \mathrm{ml})$ was added to each vial and samples were counted in a Packard Tri-Carb liquid scintillation spectrometer. Citrulline was recovered in the first $4.0 \mathrm{ml}$ of the Dowex column eluate to the extent of $96 \pm 2 \%$.

DETERMINATION OF MPO ACTIVITY

Jejunal mucosal scrapings $(200 \mathrm{mg})$ were homogenised three times for 30 seconds at $4^{\circ} \mathrm{C}$ with a polytron (Kinematica $\mathrm{GmbH}$, KriensLuzern, Switzerland) in $1.0 \mathrm{ml}$ ice-cold $0.5 \%$ hexadecyltrimethylammonium bromide in $50 \mathrm{mM}$ phosphate buffer, $\mathrm{pH}$ 6.0. The polytron probe was rinsed twice with $1.0 \mathrm{ml}$ of the buffer and the washings were added to the homogenate. The homogenate was then sonicated for 10 seconds, freeze thawed three times and centrifuged for 15 minutes at $40000 \mathrm{~g}$. An aliquot of the supernatant was taken for determination of the enzyme activity, according to Bradley et al. ${ }^{11}$

DETERMINATION OF EICOSANOID GENERATION Samples of mucosa $(150 \mathrm{mg})$ were placed in preweighed tubes containing $1.0 \mathrm{ml}$ phosphate buffer $(50 \mathrm{mM}, \mathrm{pH} 7.4)$. The mucosa was 


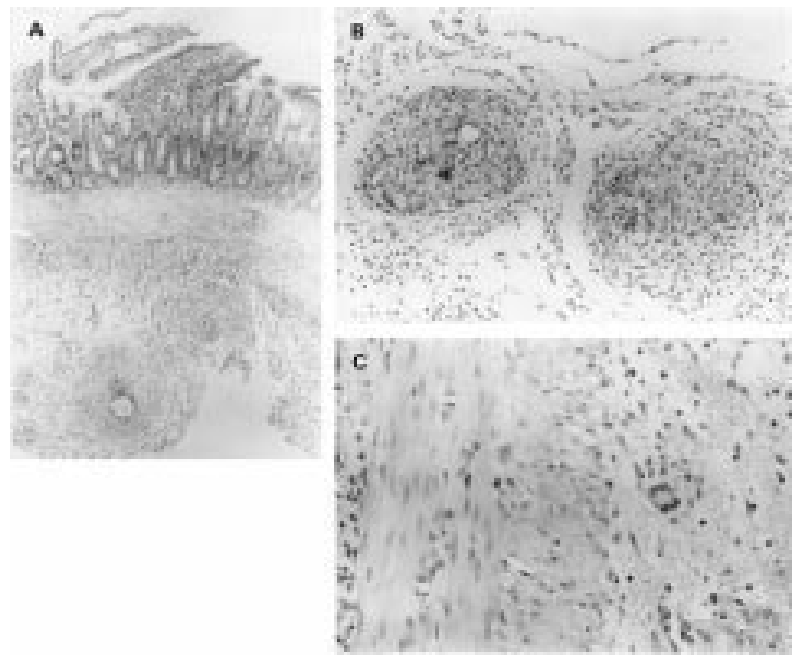

Figure 1: Effect of intraluminal iodoacetamide administration on jejunal damage. Iodoacetamide $(0.1 \mathrm{ml})(2 \%)$ was injected intrajejunally at laparotomy. Rats were sacrificed after one, seven or 14 days, the small intestine was isolated, opened and macroscopic damage was assessed as described in Methods. Control rats were injected with $0.1 \mathrm{ml} 0.9 \% \mathrm{NaCl}$. Results represent lesions in individual rats, mean (SEM).

$\star$ Significantly different from control, $p<0.05$.

minced using a scissors and centrifuged in an Eppendorf centrifuge for 10 seconds. The pellet was resuspended in $1.0 \mathrm{ml}$ phosphate buffer, incubated for one minute in a vortex mixer, $10 \mu \mathrm{g}$ indomethacin was then added, and the tubes were centrifuged for 60 seconds. The supernatants were kept at $-20^{\circ} \mathrm{C}$ pending radioimmunoassay. The capability of the mucosa to generate leukotriene $\mathrm{B}_{4}\left(\mathrm{LTB}_{4}\right)$ and leukotriene $\mathrm{C}_{4}\left(\mathrm{LTC}_{4}\right)$ was expressed as $\mathrm{ng} / \mathrm{g}$ wet tissue weight.

MEASUREMENT OF $\mathrm{LTB}_{4}$

$\mathrm{LTB}_{4}$ immunoreactivity was measured using a commercially available radioimmunoassay kit (Amersham, TRK 940). The assay combines the use of a high specific activity $\mathrm{LTB}_{4}$ tracer, an antiserum specific for $\mathrm{LTB}_{4}$ (cross-reactivity $100 \%$ ) and a leukotriene standard (range 1.6$200 \mathrm{pg} / \mathrm{tube}$ ). The specific binding of tracer is $42.5 \%$, non-specific binding $2.4 \%$. Fifty per cent $\mathrm{B} / \mathrm{Bo}$ displacement is obtained with $15 \mathrm{pg} /$ tube and $90 \% \mathrm{~B} / \mathrm{Bo}$ displacement with $2.2 \mathrm{pg} /$ tube $\mathrm{LTB}_{4}$.

MEASUREMENT OF $\mathrm{LTC}_{4}$

$\mathrm{LTC}_{4}$ immunoreactivity was also measured using a radioimmunoassay. The assay combines the use of a high specific activity $\mathrm{LTC}_{4}$ tritiated tracer with a monoclonal antibody specific for $\mathrm{LTC}_{4}$ and $\mathrm{LTC}_{4}$ standard (8$500 \mathrm{pg} /$ tube). The assay uses highly specific $\mathrm{LTC}_{4}$ antiserum (cross-reactivity 100\%) and has low cross-reactivity with leukotriene $\mathrm{D}_{4}$ $\left(\mathrm{LTD}_{4}\right)(<5 \%)$. The specific binding of tracer is $40-45 \%$ and non-specific binding is $1-3 \%$. Fifty per cent B/Bo displacement is obtained with $34 \mathrm{pg} /$ tube, and $80 \% \mathrm{~B} /$ Bo displacement with $9.5 \mathrm{pg} /$ tube $\mathrm{LTC}_{4}$. The percentage coefficient of variation (CV) for within assay precision ranges from 7.68 (low) to 3.94 (high). The percentage $\mathrm{CV}$ for the precision profile of the assay ranges from 1.64 to $3.49(n=9)$.
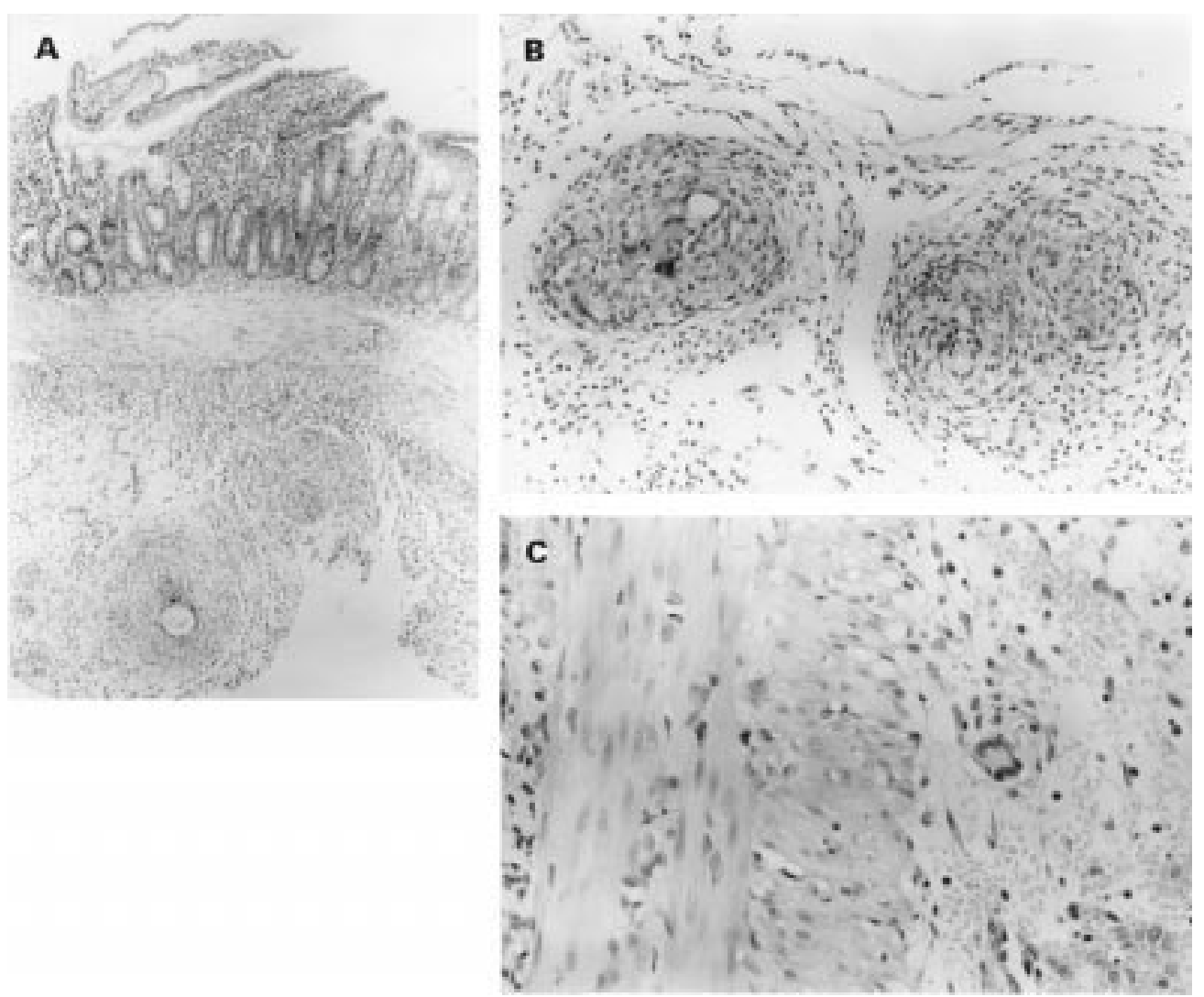

Figure 2: (A) Histological section of the jejunum isolated from rats seven days after intraluminal injection of iodoacetamide showing mucosal ulceration with many epithelioid granulomas in the submucosa (haematoxylin and eosin; original magnification $\times 73$ ). (B) Higher magnification of section A showing epitheloid granulomas with giant cells and giant Langhans cells (original magnification $\times 183$ ). (C) Giant cell (magnification of section B $\times 292$ ). 
TABLE 1 Scoring of histological changes following iodoacetamide treatment

\begin{tabular}{|c|c|}
\hline Score & Histological change(s) \\
\hline 1 & Very mild inflammatory infiltrate \\
\hline 2 & Mild inflammatory infiltrate with minute ulceration of the mucosa \\
\hline 3 & $\begin{array}{l}\text { Moderate inflammatory cell infiltrate with multiple small mucosal ulcerations } \\
\text { involving the mucosa and submucosa }\end{array}$ \\
\hline 4 & $\begin{array}{l}\text { Extensive inflammatory cell infiltrate involving the mucosa and submucosa, with } \\
\text { widespread ulceration. The inflammatory cell infiltrate also invades the muscularis } \\
\text { propria }\end{array}$ \\
\hline
\end{tabular}

TABLE 2 Histological changes in the jejunum after treatment with iodoacetamide

\begin{tabular}{llcc}
\hline Variable & Score & \\
\hline Days after treatment & 1 & 7 & 14 \\
No. of rats & 6 & 14 & 7 \\
Inflammatory infiltrate score & $3.8(0.17)$ & $2.6(0.3)$ & $2.1(0.3)$ \\
No. of rats with granuloma & 0 & 10 & 4 \\
Granuloma/section & 0 & $1.6(0.4)$ & $1.4(0.6)$ \\
\hline
\end{tabular}

Results are expressed as mean (SE).

Rats were treated with $0.1 \mathrm{ml}$ iodoacetamide $(2 \%)$ administered intrajejunally and sacrificed after 1-14 days. The proximal $25 \mathrm{~cm}$ of the jejunum was isolated and sections processed for histology. The inflammatory infiltrate was scored as described in Methods and table 1.

TABLE 3 Effect of exposure to iodoacetamide in a closed loop on small intestinal injury, weight and NOS activity

\begin{tabular}{lllll}
\hline & & \multicolumn{2}{l}{ Days after treatment } \\
\cline { 3 - 5 } & No treatment & 1 & 7 & 14 \\
\hline No. of rats & $23-27$ & $4-10$ & 7 & 14 \\
Lesion $\left(\mathrm{mm}^{2} / \mathrm{rat}\right)$ & 0 & $267(87)^{\star}$ & $1423(566)^{\star}$ & $3437(817)^{\star}$ \\
Range & 0 & $12-960$ & $528-3625$ & $105-9600$ \\
Median & 0 & 292 & 1100 & 2500 \\
Weight $(\mathrm{g} / 25 \mathrm{~cm})$ & $1.50(0.05)$ & $1.62(0.12)$ & $4.4(0.5)^{\star}$ & $5.25(0.67)^{\star}$ \\
NOS $(\mathrm{nmol} / \mathrm{g} / \mathrm{min})$ & $2.76(0.10)$ & $4.8(0.2)^{\star}$ & $7.5(0.2)^{\star}$ & $22.8(0.6)^{\star}$ \\
\hline
\end{tabular}

Results are expressed as mean (SE).

Under light ether anaesthesia, the jejunum was identifed, a $10 \mathrm{~cm}$ loop was closed and injected with $0.1 \mathrm{ml}$ iodoacetamide $(2 \%)$. Control rats (no treatment) underwent laparotomy and were injected with $0.1 \mathrm{ml}$ methyl cellulose $(1 \%)$. Thirty minutes later, the loop was opened, returned to the abdominal cavity and the abdominal wall was closed. Rats were sacrificed one, seven and 14 days after treatment, the proximal $25 \mathrm{~cm}$ of the jejunum was isolated, weighed, and lesions were assessed and mucosal NOS activity determined as described in Methods.

${ }^{\star}$ Significantly different from no treatment $(\mathrm{p}<0.05)$.

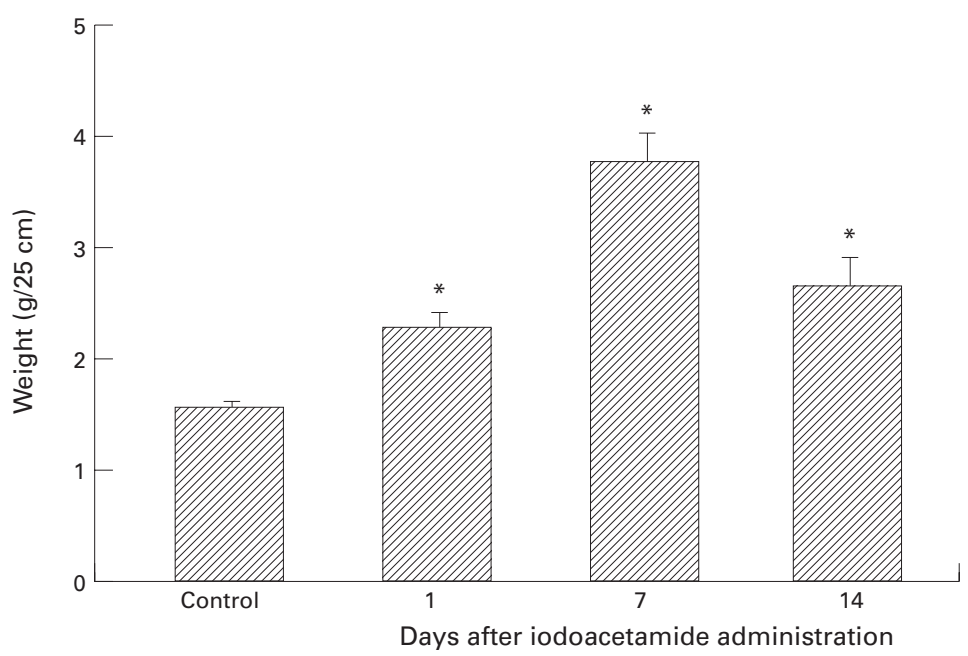

Figure 3: Effect of intraluminal administration of iodoacetamide on jejunal wet weight. Iodoacetamide $(0.1 \mathrm{ml})(2 \%)$ was injected intrajejunally at laparotomy. Rats were sacrificed after one, seven or 14 days, the small intestine was isolated, opened and macroscopic damage was assessed as described in Methods. Control rats were injected with $0.1 \mathrm{ml} 0.9 \% \mathrm{NaCl}$, the affected small intestine was isolated, weighed and its length measured. Results are mean (SEM) of seven to 17 rats in each group. *Significantly different from control, $p<0.05$.
MEASUREMENT OF $\mathrm{PGE}_{2}$

$\mathrm{PGE}_{2}$ was determined by radioimmunoassay as described previously. ${ }^{12}$

MEASUREMENT OF $\mathrm{TXB}_{2}$ $\mathrm{TXB}_{2}$ immunoreactivity was measured by enzyme immunoassay (Amersham RPN 220).

The assay combines the use of a peroxidase labelled $\mathrm{TXB}_{2}$ conjugate, a specific antiserum which can be immobilised onto a precoated microtitre plate (cross-reactivity $100 \%$ ) and a $\mathrm{TXB}_{2}$ standard (0.5-64 pg/well). Fifty per cent displacement is obtained with $6 \mathrm{pg} /$ well and $90 \%$ with $1 \mathrm{pg} /$ well.

\section{MORPHOLOGICAL STUDIES}

Sections were obtained from the same areas of the small intestine, during necropsy, from animals in each of the treatment groups. They were fixed in phosphate buffered formaldehyde, embedded in paraffin wax and routine $5 \mu \mathrm{m}$ sections were prepared. Tissues were stained routinely with haematoxylin and eosin and were evaluated by light microscopy by a pathologist unaware of the experimental protocol. The histological changes were scored as outlined in table 1 .

\section{STATISTICAL ANALYSIS}

Data are expressed as mean (SEM). Statistical analysis for significant differences was performed using the Student's $t$ test for paired and unpaired data and the non-parametric MannWhitney U test. Differences were considered significant for $\mathrm{p}$ values $<0.05$.

\section{Results}

Intraluminal administration of $0.1 \mathrm{ml}$ iodoacetamide $(2 \%)$ induced jejunal mucosal erosions and ulcerations that were apparent after 24 hours and maximal at seven days (1648 (418) $\mathrm{mm}^{2} / \mathrm{rat}, \mathrm{n}=15$ ). Control rats were not affected. Two weeks after treatment the mucosa was almost intact in 12 of 17 rats (fig 1). Histologically, 24 hours after treatment there was widespread mucosal ulceration with extensive inflammatory cell infiltrate and haemorrhage. At seven days minute ulceration of the villous surface with acute and chronic inflammatory cell infiltrate in the lamina propria was observed. There were many epithelioid cells and granulomas on the serosa in 10 of 14 rats. In several animals giant Langhans cells were found with widespread ulceration, fissure formation and inflammatory granulation tissue (fig 2). Fourteen days after treatment, in four of seven rats histology revealed a chronic inflammatory process with granulomas and giant Langhans cells (table 2). The wet weight of the jejunal segment, a sensitive marker of inflammation, was also maximal at seven days (3.80 $(0.25) \mathrm{g} / 25 \mathrm{~cm})$ and significantly higher $(\mathrm{p}<0.05)$ than that of control rats $(1.55$ $(0.05) \mathrm{g} / 25 \mathrm{~cm}$; fig 3 ). In rats treated with iodoacetamide MPO activity 24 hours after administration was 3.5-fold higher than its activity in control rats, $5.4(0.5)$ and 1.36 (0.10) units/g, respectively. At all other time intervals there was no significant difference in 


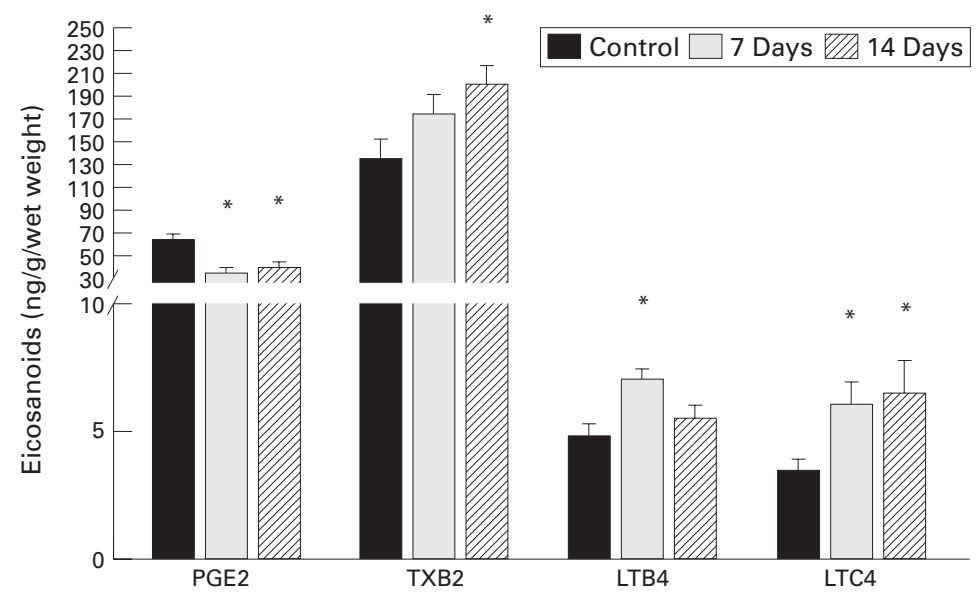

Figure 4: Effect of intraluminal administration of iodoacetamide on jejunal production of $P G E_{2}, T X B_{2}, L T B_{4}$, and $L T C_{4}$. Iodoacetamide $(0.1 \mathrm{ml})(2 \%)$ was injected intrajejunally at laparotomy. Rats were sacrificed after one, seven or 14 days, the small intestine was isolated, opened and macroscopic damage was assessed as described in Methods. Control rats were injected with $0.1 \mathrm{ml} 0.9 \% \mathrm{NaCl}$, the mucosa was scraped and processed for determination of $\mathrm{PGE}_{2}, T X B_{2}, L T B_{4}$, and $L T C_{4}$ generation as described in Methods. Results are mean (SEM) of seven to 17 rats in each time interval. ${ }^{\star}$ Significantly different from control, $p<0.05$.

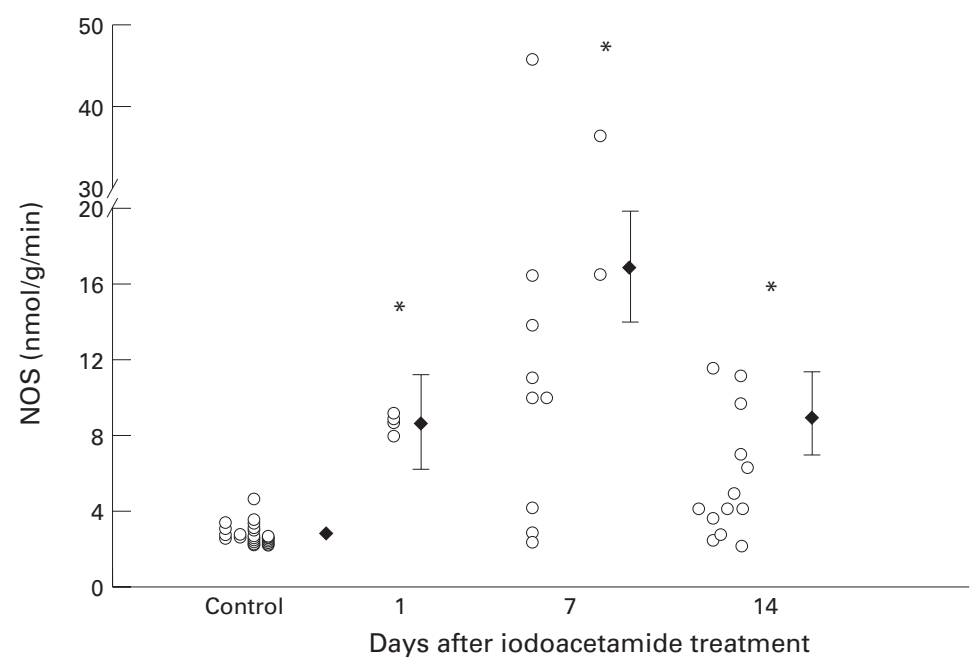

Figure 5: $\quad$ Effect of intraluminal iodoacetamide administration on jejunal NOS activity. Iodoacetamide $(0.1 \mathrm{ml})$ (2\%) was injected intrajejunally at laparotomy. Rats were sacrificed after one, seven or 14 days, the small intestine was isolated, opened and the mucosa was scraped and processed for determination of NOS activity as described in Methods. Control rats were injected with $0.1 \mathrm{ml} 0.9 \% \mathrm{NaCl}$. Results are mean (SEM) of determinations performed with tissue obtained from four to 14 rats. ${ }^{\star}$ Significantly different from control, $p<0.05$.

TABLE 4 Effect of TEMPOL, L-NAME, apocynin, and ketotifen on jejunal weight, mucosal lesions, leukotriene generation, and NOS activity in iodoacetamide treated rats

\begin{tabular}{llllll}
\hline Treatment & None & TEMPOL & L-NAME & Apocynin & Ketotifen \\
\hline No. of rats & $7-14$ & $8-14$ & 8 & $8-10$ & 7 \\
Weight $(\mathrm{g} / 25 \mathrm{~cm})$ & $3.80(0.25)$ & $4.0(0.2)$ & $3.7(0.4)$ & $2.40(0.07)^{\star}$ & $2.00(0.07)^{\star}$ \\
Lesion $\left(\mathrm{mm}^{2} / \mathrm{rat}\right)$ & $1684(418)$ & $2551(515)$ & $1322(444)$ & $26.0(5.0)^{\star}$ & $5.0(5.0)^{\star}$ \\
Range & $420-6820$ & $600-7200$ & $0-3900$ & $0-56$ & $0-35$ \\
Median & 1100 & 2035 & 1140 & 30 & 0 \\
NOS & & & & & \\
$\quad(\mathrm{nmol} / \mathrm{g} / \mathrm{min})$ & $16.90(2.97)$ & $21.8(2.7)$ & $18.50(2.75)$ & $3.00(0.26)^{\star}$ & $3.90(0.39)^{\star}$ \\
$\mathrm{LTB}_{4}(\mathrm{ng} / \mathrm{g})$ & $7.10(0.45)$ & $3.2(0.7)^{\star}$ & $1.5(0.5)^{\star}$ & $5.60(0.56)$ & $5.0(1.0)$ \\
$\mathrm{LTC}_{4}(\mathrm{ng} / \mathrm{g})$ & $6.60(1.28)$ & $2.9(0.4)^{\star}$ & $3.10(0.77)^{\star}$ & $3.97(0.95)$ & $8.0(1.5)$ \\
PGE $_{2}(\mathrm{ng} / \mathrm{g})$ & $37.0(6.2)$ & $28.3(5.6)$ & $21.7(5.7)$ & $49.5(7.5)^{\star}$ & $54.0(5.0)^{\star}$ \\
\hline$R^{25 u l s a r e x p}$ & & & &
\end{tabular}

Results are expressed as mean (SE).

Rats were injected intrajejunally with $0.1 \mathrm{ml}$ iodoacetamide $(2 \%)$ and co-treated daily intragastrically with TEMPOL ( $50 \mathrm{mg} / 100 \mathrm{~g}$ body weight) or ketotifen $(200 \mu \mathrm{g}$ body weight). Other groups were co-treated with L-NAME $(0.1 \mathrm{mg} / \mathrm{ml})$ or apocynin $(120 \mu \mathrm{g} / \mathrm{ml})$ added to the drinking water. The control group was treated with iodoacetamide only. Rats were sacrificed after seven days, the small intestine was isolated, the proximal $25 \mathrm{~cm}$ section was weighed, lesions were measured, and mucosal NOS activity, and production of $\mathrm{LTB}_{4}, \mathrm{LTC}_{4}$ and $\mathrm{PGE}_{2}$ measured as described in Methods.

*Significantly different from rats treated with iodoacetamide only $(\mathrm{p}<0.05)$.
MPO activity between control and iodoacetamide treated rats.

Iodoacetamide treatment induced a small but significant decrease in mucosal generation of $\mathrm{PGE}_{2}$ seven and 14 days after its administration (fig 4). Generation of $\mathrm{LTB}_{4}$ and $\mathrm{LTC}_{4}$ was increased significantly seven days after intraluminal administration of iodoacetamide, whereas only $\mathrm{TXB}_{2}$ and $\mathrm{LTC}_{4}$ production was significantly increased 14 days after treatment (fig 4). Jejunal NOS activity was stimulated significantly up to 14 days in iodoacetamide treated rats compared with its activity in control rats. Maximal activity was noted at seven days (fig 5). Deletion of calcium in vitro had no effect on basal jejunal NOS activity in control rats. Aminoguanidine and valine significantly decreased basal jejunal NOS activity whereas L-NAME dose dependently inhibited NOS activity (fig 6). After exposure to iodoacetamide for 30 minutes in a closed loop jejunal damage was apparent after 24 hours and persisted for 14 days. Wet weight and mucosal NOS activities were increased significantly at all time periods (table 3 ).

In rats treated with iodoacetamide added to the drinking water $(0.1 \mathrm{mg} / \mathrm{ml})$ no macroscopic jejunal mucosal damage was observed at any of the time intervals. However, jejunal wet weight and NOS activity were significantly higher in rats treated for two and four weeks compared with control rats (fig 7). Histologically, after 28 days of treatment small, superficial mucosal ulcerations with mild, chronic inflammatory cell infiltrate were observed (fig 8).

Addition of L-NAME $(0.1 \mathrm{mg} / \mathrm{ml})$ to the drinking water at the time of induction of jejunal injury by intraluminal administration of iodoacetamide or intragastric administration of TEMPOL, given daily at a dose of $50 \mathrm{mg} /$ $100 \mathrm{~g}$ body weight, did not affect the macroscopic or microscopic extent of jejunal injury. Histologically, there was extensive mucosal ulceration with granuloma tissue formation and extensive cell infiltrate. The wet weight of the jejunal segment and mucosal NOS activity were similar to those measured in rats treated with iodoacetamide only. Seven days of treatment with TEMPOL or L-NAME decreased leukotriene generation significantly compared with its generation in rats treated with iodoacetamide only, but had no effect on mucosal production of $\mathrm{PGE}_{2}$ (table 4). The addition of apocynin $(120 \mu \mathrm{g} / \mathrm{ml})$ to the drinking water, or daily intragastric administration of ketotifen $(200 \mu \mathrm{g} / 100 \mathrm{~g}$ body weight $)$ at the time of induction of jejunal injury with iodoacetamide resulted in an effective decrease in the extent and severity of jejunal damage. The protective effect provided by apocynin or ketotifen was accompanied by significant decreases in the wet weight and in jejunal NOS activity. The amelioration of mucosal damage was accompanied by a significant increase in $\mathrm{PGE}_{2}$ generation to a level similar to that observed in control rats, whereas mucosal leukotriene generation was not affected by ketotifen or apocynin (table 4). Histologically, in apocynin (fig 9) and ketotifen (fig 10) treated rats, at 


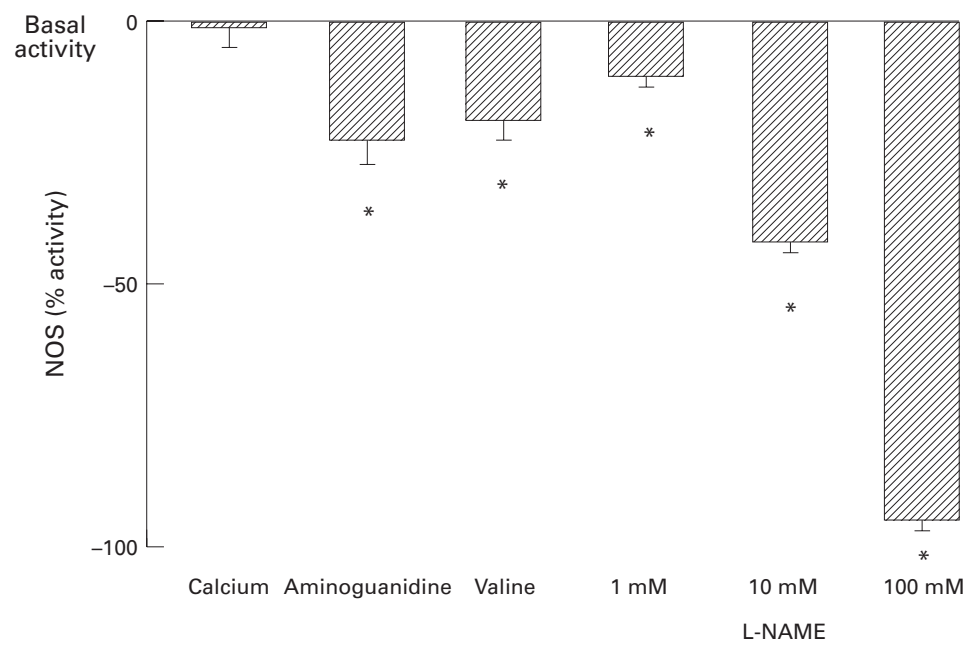

Figure 6: Fejunal mucosal NOS activity in normal rats was determined in the presence or absence of calcium, aminoguanidine $(10 \mathrm{mM})$, valine $(60 \mathrm{mM})$ or $L-N A M E$

(1-100 mM) as described in Methods. Basal activity was 2.7 (0.1) nmol/g/min and was regarded as $100 \%$. Results are mean (SEM) of determinations performed with tissue obtained from four to 14 rats. ${ }^{\star}$ Significantly different from basal activity, $p<0.05$.

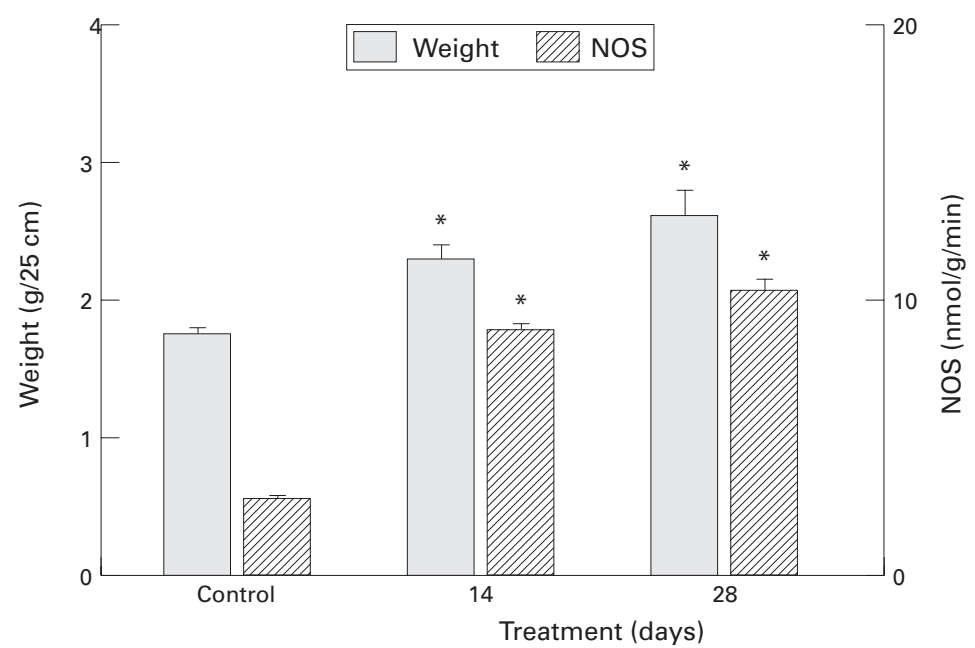

Figure 7: Effect of iodoacetamide added to the drinking water on small intestinal weight and NOS activity. Rats were sacrificed two or four weeks after exposure to iodoacetamide $(0.1 \%)$ added to the drinking water. The upper $25 \mathrm{~cm}$ of the small intestine was isolated, weighed and mucosal NOS activity determined as described in Methods. Control rats were given ordinary water. Results are mean (SEM) of five to eight rats in each time interval. ${ }_{*}$ Significantly different from control, $p<0.05$.

seven days the villi were almost normal with a mild inflammatory cell infiltrate and granulomas were not observed in any of the rats.

\section{Discussion}

Models of experimental inflammation in the gut, mimicking human IBD, have become very popular in recent years. The crude models which use chemicals, haptens and immunological manipulations to induce inflammation have lost some of their popularity with the development of genetic manipulation. ${ }^{1}$ The region of intestinal involvement is also important in view of the different areas of the intestine affected in ulcerative colitis and Crohn's disease. Confinement of ulcerative colitis to the colon as opposed to the possible involvement of any region of the gut in Crohn's disease may be because of specific regional environmental factors. Obviously, bacteria are one of the possible environmental factors which differ along the gut, though their contribution to the aetiology or pathogenesis of IBD has, so far, never been proved.

Despite the high incidence of small intestinal involvement in Crohn's disease, most available models of intestinal inflammation are models of experimental colitis and only a few deal with the small intestine. The models established in the small intestine include a model in mice, in which damage is induced by lipopolysaccharide (LPS), ${ }^{13}$ acetic acid induced small intestinal damage in rats, ${ }^{14}$ TNB induced ileitis in guinea pigs, ${ }^{2}$ and indomethacin induced jejunal injury in rats. ${ }^{15}$ In this study we describe a new model of small intestinal inflammation induced in rats by the $\mathrm{SH}$ blocker, iodoacetamide.

Glutathione, in combination with its reduced form, GSH, has an important role in the maintenance of mucosal integrity in the gastrointestinal tract. $\mathrm{GSH}$ is a scavenger of $\mathrm{O}_{2}^{-}$ and is a cofactor in the reduction of hydrogen peroxide. ${ }^{16}$ In the upper gastrointestinal tract GSH is essential for protection against oxidative damage induced by $\mathrm{SH}$ blockers. ${ }^{16} \mathrm{Re}-$ cently, we reported a new model of experimental colitis induced by the $\mathrm{SH}$ blocker, iodoacetamide. ${ }^{9}$ The inflammation induced in the small intestine by iodoacetamide in this model reached a maximum seven days after exposure. The superficial mucosal damage was also accompanied by an increase in the wet weight of the exposed segment, a very sensitive marker of inflammation in the gut. ${ }^{17}$

The unique feature of the model presented in this study is the very close resemblance of the microscopic lesions to the pathological changes in the inflamed gut of patients with Crohn's disease. Unlike the models described previously, epitheloid granuloma with giant Langhans cells were seen. Moreover, as in Crohn's disease, the typical histological changes are also present in regions not affected macroscopically. This observation was noted in the present study 14 days after intrajejunal administration of iodoacetamide and also in rats treated for 28 days with iodoacetamide added to their drinking water. The similarity between the histological changes in Crohn's disease and in iodoacetamide induced small intestinal damage suggests that $\mathrm{SH}$ blockers are involved in the pathogenesis of Crohn's disease.

At the time of maximal tissue damage in the small intestine, mucosal production of $\mathrm{LTB}_{4}$ and $\mathrm{LTC}_{4}$ was increased, whereas production of $\mathrm{PGE}_{2}$ was decreased significantly. This pattern has also been reported in models of experimental colitis. ${ }^{917}$ However, the decrease in mucosal $\mathrm{PGE}_{2}$ generation is typical of the damage induced by iodoacetamide in the small intestine. In colitis induced by iodoacetamide, acetic acid and TNB, colonic production of $\mathrm{PGE}_{2}$ is increased. ${ }^{9}$ In the stomach and, perhaps also in the small intestine, $\mathrm{PGE}_{2}$ has protective properties, ${ }^{18}$ whereas in the colon, $\mathrm{PGE}_{2}$ may be regarded as one of the proinflammatory mediators, as in other organs. ${ }^{19}$ The contribution of $\mathrm{TXB}_{2}$ to the pathogenesis of iodoacetamide induced small intestinal inflammation is not significant as at seven days 


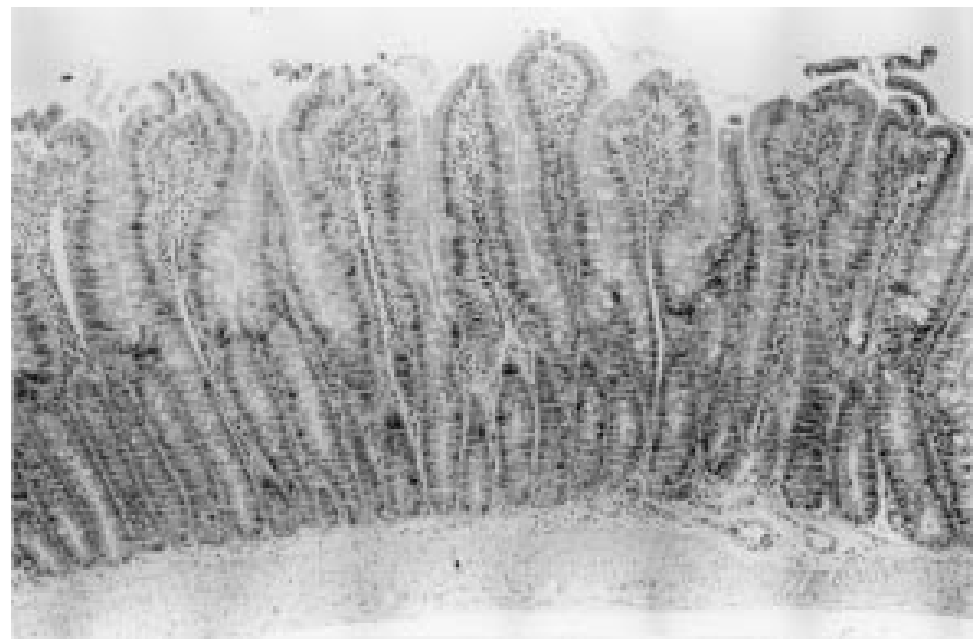

Figure 8: Section obtained from a rat treated with iodoacetamide added to the drinking water for one month, showing small superficial ulcerations at the tip of the villi accompanied by mild inflammatory cell infiltrate in the lamina propria (haematoxylin and eosin; original magnification $\times 73$ ).

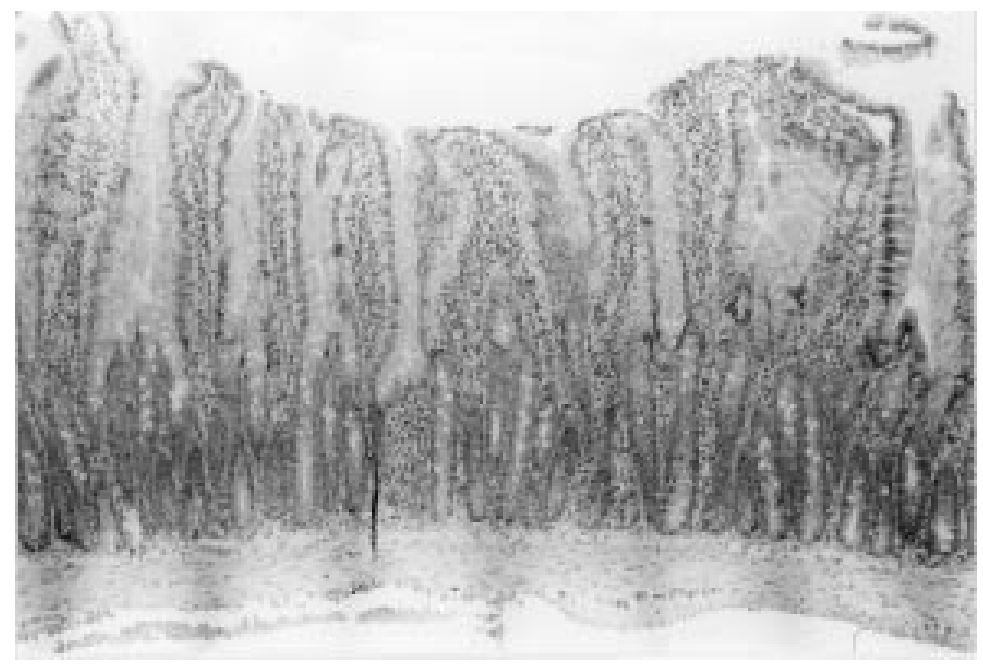

Figure 9: Cross section of the jejunal wall in a rat seven days after intraluminal injection of iodoacetamide and treated daily with apocynin. Note the normal villi and mild inflammatory infiltrate (haematoxylin and eosin; original magnification $\times 73$ ).

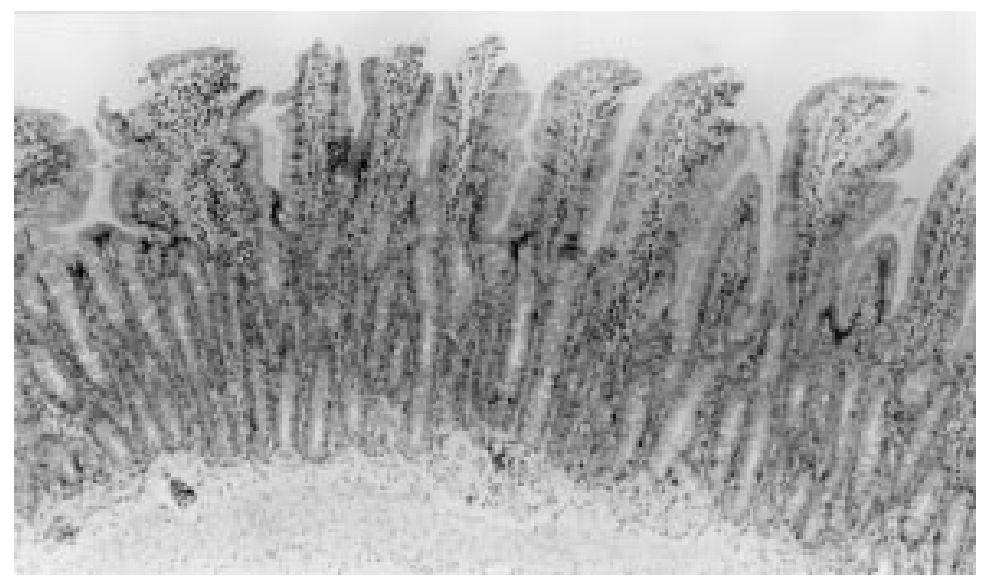

Figure 10: Section from a rat seven days after intraluminal injection of iodoacetamide and daily treatment with ketotifen. Villi are almost normal and only very mild inflammatory cell infiltrate is evident (haematoxylin and eosin; original magnification $\times 73)$. when injury was maximal, its generation was not stimulated.

Mucosal NOS activity is stimulated in iodoacetamide induced small intestinal inflammation. Intestinal NO generation is increased in models of experimental colitis, as well as in patients with IBD. ${ }^{20}$ The increase in NO output by small intestinal mucosa in response to injurious insults may amplify tissue injury by combining with superoxide, generated simultaneously by inflammatory cells, to produce peroxynitrite, which causes severe colonic damage. $^{21}$

It is conceivable that the free radicals NO and $\mathrm{O}_{2}^{-}$are the final agents responsible for tissue damage. The major contribution of $\mathrm{O}_{2}{ }^{-}$to the pathogenesis of tissue injury in this model is illustrated further in this study by the impressive protection provided by apocynin, a NADPH oxydase inhibitor. NADPH oxidases produce reactive oxygen species in neutrophils and inhibition of these enzymes by apocynin reduces sepsis following injury to the lung, ${ }^{22}$ and collagen induced arthritis. ${ }^{23}$

TEMPOL, the potent free radical scavenger, which ameliorates injury in the upper ${ }^{24}$ and lower $^{25}$ gastrointestinal tract, did not protect against iodoacetamide induced small intestinal injury. Its lack of efficacy may be because of lack of sufficient scavenging capacity needed to overcome extensive $\mathrm{O}_{2}^{-}$production in this model. Similarly, inhibition of NOS activity, shown to decrease the extent of tissue injury effectively in other models, including iodoacetamide induced colitis, ${ }^{9}$ had no protective effect in this model. It seems, therefore, that NO has a different role in the pathogenesis of injury along the various regions of the gastrointestinal tract. In the stomach, NO is essential for the maintenance of mucosal integrity and a reduction in its generation is deleterious, ${ }^{26}$ whereas in the small intestine, L-NAME was unable to inhibit the stimulated NOS activity induced by iodoacetamide.

Ketotifen provides effective protection against iodoacetamide induced small intestinal damage. Ketotifen ameliorates injury induced by various agents in the stomach, ${ }^{27}$ colon $^{28}$ and in the small intestine, ${ }^{29}$ and may prevent the release of pro-inflammatory mediators from mast cells. ${ }^{30}$ In view of its potent protective effect against iodoacetamide induced jejunal lesions, treatment with ketotifen should be considered for the prevention of relapse in Crohn's disease.

In conclusion, we have characterised a new model of small intestinal inflammation induced by an $\mathrm{SH}$ blocker which produces pathological features greatly resembling those of Crohn's disease. This model suggests that $\mathrm{SH}$ blockers may be involved in the pathogenesis of Crohn's disease. Moreover, the important role of oxygen free radicals and inflammatory mediators in the pathogenesis of small intestinal inflammation is illustrated by the effective modulation of the model provided by apocynin and ketotifen. 
1 Elson CO, Sartor RB, Tennyson GS, Riddell RH Experimental models of inflammatory bowel disease. Gas troenterology 1995; 109: 1344-67.

2 Miller MJS, Sadowska-Krowicka A, Chotinaruemol S, Kakkis JL, Clark DA. Amelioration of chronic ileitis by nitric oxide synthase inhibition. F Pharmacol Exp Ther 1993; 264: $11-6$.

3 Yamada T, Deitch E, Specian RD, Perry MA, Sartor RB, Grisham MB. Mechanisms of acute and chronic intestinal inflammation induced by indomethacin. Inflammation 1993; 17: 641-62.

4 Sartor RB, Cromartie WJ, Powell DW, Schwab JH. Granulomatous enterocolitis induced in rats by purified bacterial cell wall fragments. Gastroenterology 1985; 89: 587-95.

5 Hammer RE, Maika SD, Richardson JA, Tang JP, Taurog JD. Spontaneous inflammatory disease in transgenic rats expressing HLA-B27 and human beta $2 \mathrm{~m}$ : An animal model of HLA-B27-associated human disorders. Cell 1990; 63: 1099-112.

6 Kuhn R, Lohler J, Rennick D, Rajewsky K, Muller W. Interleukin-10-deficient mice develop chronic enterocoliInterleukin-10-deficient mic
tis. Cell 1993; 75: 263-74.

7 Shibata Y, Taruishi M, Ashida T. Experimental ileitis in dogs and colitis in rats with trinitrobenzene sulfonic acidColonoscopic and histopathologic studies. Gastroenterologica faponica 1993; 28: 518-27.

8 Osborne MJ, Hudson M, Piasecki C, Dhillon AP, Lewis AA Pounder RE, Wakefield AJ. Crohn's disease and anastomotic recurrence: Microvascular ischaemia and anastomotic healing in an animal model. Br f Surg 1993; 80: 226-9.

9 Rachmilewitz D, Karmeli F, Okon E. Sulphydryl blockerinduced colonic inflammation is ameliorated by inhibition of nitric oxide synthase activity. Gastroenterology 1995; 109: 98-106.

10 Bush PA, Gonzalez NE, Griscavage JM, Ignarro LJ. Nitric oxide synthase from cerebellum catalyzes the formation of equimolar quantities of nitric oxide and citrulline from L-arginine. Biochem Biophys Res Commum 1992; 185:

11 Bradley PP, Priebat DA, Christensen RD, Rothstein G. Measurement of cutaneous inflammation: Estimation of neutrophil content

12 Sharon P, Ligumsky M, Rachmilewitz D, Zor U. Role of prostaglandins in ulcerative colitis: Enhanced production during active disease and inhibition by sulphasalazine. Gastroenterology 1978; 65: 638-40.

13 Meyer TA, Wang J, Tiao GM, Ogle CK, Fisher JE, Hasselgren PO. Sepsis and endotoxemia stimulate intestinal interleukin-6 production. Surgery 1995; 118: $336-42$.

14 Miller MJ, Zhang XJ, Gu XA, Clark D. Acute intestinal injury induced by acetic acid and casein: Prevention by intraluminal misoprostol. Gastroenterology 1991; 101: 2230.

15 Nygard G, Anthony A, Piasecki C, Trevethick MA, Hudson $\mathrm{M}$, Dhillon AP, et al. Acute indomethacin jejunal injury in the rat: Early morphological and biochemical changes. Gastroenterology 1994; 106: 567-75.
16 Meister A, Anderson ME. Glutathione. Ann Rev Biochem 1983; 52: 711-60.

17 Rachmilewitz D, Simon PL, Schwartz LW, Griswold DE, Fondacaro JD, Wasserman MA. Inflammatory mediators of experimental colitis in rats. Gastroenterology 1989; 97: 326-37.

18 Robert A, Nezamis JE, Lancaster C, Hanchar AJ. Cytoprotection by prostaglandins in rats-Prevention of gastric necrosis produced by alcohol, $\mathrm{HCl}, \mathrm{NaOH}$, hypertonic $\mathrm{NaCl}$ and thermal injury. Gastroenterology 1979; 77: 433-43.

19 Ferreira SH, Moncada S, Vane JR. Prostaglandins and signs and symptoms of inflammation. In: Robinson HJ, Vane JR, eds. Prostaglandin synthetase inhibitors. New York: Raven Press, 1974: 175-87.

20 Rachmilewitz D, Stamler JS, Bachwich D, Karmeli F, Ackerman Z, Podolsky DK. Enhanced colonic nitric oxide generation and nitric oxide synthase activity in ulcerative colitis and Crohn's disease. Gut 1995; 36: 718-23.

21 Rachmilewitz D, Stamler JS, Karmeli F, Mullins ME, Singel $\mathrm{D}$, Loscalzo J, et al. Peroxynitrite-induced rat colitis-A new model of

22 Wang W, Suzuki Y, Tanigaki T, Rank DR, Raffin TA. Effect of the NADPH oxidase inhibitor apocynin on septic lung injury in guinea pigs. Am F Respir Crit Care Med 1994; 150: 1449-52.

23 t-Hart BA, Bakkr NP, Labadie RP, Simons JM. The newly developed neutrophil oxidative burst antagonist apocynin inhibits joint-swelling in rat collagen arthritis. Agents Actions Suppl 1991; 32: 179-84.

24 Rachmilewitz D, Karmeli F, Okon E, Samuni A. A novel anti-ulcerogenic stable radical prevents gastric mucosal lesions in rats. Gut 1994; 35: 1181-8.

25 Karmeli F, Eliakim R, Okon E, Samuni A, Rachmilewitz D. A stable nitroxide radical effectively decreases mucosal damage in experimental colitis. Gut 1995; 37: 386-93.

26 Karmeli F, Okon E, Rachmilewitz D. Sulphydryl blocker induced gastric damage is ameliorated by scavenging of free radicals. Gut 1996; 38: 826-31.

27 Karmeli F, Eliakim R, Okon E, Rachmilewitz D. Role of vasoactive intestinal peptide (VIP) in the pathogenesis of ethanol induced gastric mucosal damage in rats. Dig Dis Sci 1993; 38: 1210-9.

28 Eliakim R, Karmeli F, Okon E, Rachmilewitz D. Ketotifen effectively prevents mucosal damage in experimental colitis. Gut 1992; 33: 1498-503.

29 Pothoulakis C, Karmeli F, Kelly CP, Eliakim R, Joshi MA, O'Keane JO, et al. Mast cell involvement in Clostridium difficile toxin A enteritis in rat: Studies with ketotifen. Gastroenterology 1993; 105: 701-7.

30 Friedman ZY, Selinger Z, Karmeli F, Eliakim R, Rachmilewitz D. Enhanced colonic inositol phosphate generation in Crohn's disease and inhibition of its breakdown by ketotifen [abstract]. Gastroenterology 1992; 102: A623. 